\title{
Genotype characterization of human papillomavirus in women infected and uninfected with HIV in Ouagadougou, Burkina Faso
}

\author{
Florencia W Dkigma*, Djeneba Ouermi, Tani Sagna, Charlemagne Ouedraogo, Cyrille Bisseye, Moctar Zeba, \\ Simplice D Karou, Virginio Pietra, Jean-Baptiste Nikiema, Jacques Simpore \\ From 17th International Symposium on HIV and Emerging Infectious Diseases (ISHEID) \\ Marseille, France. 23-25 May 2012
}

\section{Introduction}

Our study aims to compare the prevalence and genotypes of HPV in HIV-positive and negative women in Ouagadougou, where HIV and HPV prevalence are respectively estimated at $4.0 \%$ and $24 \%$.

\section{Materials and methods}

The study involved 410 women: 205 HIV-positive followed by two sites of HIV/AIDS care in the eastern outskirts of Ouagadougou, matched by age with 205 HIVnegative consulting the gynaecological services in the same area. HPV genotyping was done by PCR followed by reverse hybridization on nitrocellulose strips with the kit "STAR HPV Blot" (Diatech ${ }^{\circledR}$, Italy).

\section{Results}

Prevalence of HPV was: $25.4 \%$ among HIV-negative women and $59.0 \%$ among HIV-positive women ( $\mathrm{p}$ $<0.01)$. Means of age was respectively $33.6(\mathrm{SD} \pm 8.6)$ versus 33.4 (SD \pm 6.4$)$. Prevalence of HPV subtypes at low risk of oncogenicity $(6,11, \mathrm{LR})$ among HIV-positive women was $9.8 \%$ and $9.3 \%$ in the control group $(\mathrm{p}=\mathrm{ns})$. Prevalence of HPV subtypes at high risk of oncogenicity was significantly $(\mathrm{p}<0.01)$ higher among HIV-positive women for subtypes 50 'S (22.0\% versus $9.3 \%$, OR=2.8; CL95\% 1.5-5.1), 18 (20.0\% versus $2.9 \%$, OR $=8.3$; CL95\% $3.2-23.0)$, 30'S (17.6\% versus $1.5 \%$, OR $=14.3$; CL95\% 4.1-60.1) and HR ( 7.3\%, versus $1.0 \%$, OR=8.0 ; CL95\% 1.7-52.1) while no significant difference was observed for high risk subtypes 16 and 45 . Co-infections by two or more subtypes at high risk were detected in $27 / 205$

\footnotetext{
* Correspondence: flodjig@yahoo.fr
Centre de Recherche Biomoléculaire «Pietro Annigoni »CERBA/LABIOGENE,

* Correspondence: flodjig@yahoo.fr
Centre de Recherche Biomoléculaire «Pietro Annigoni »CERBA/LABIOGENE, Ouagadougou, Burkina Faso
}

(13.2\%) HIV-positive women and 3/205 (1.5\%) HIVnegative women $(\mathrm{p}<0.01$; OR 10.2; CL95\% 2.9-43.5). Among HIV-positive women, prevalence of oncogenic subtypes was significantlycorrelated with a lower CD4 count $(\mathrm{P}=0.05)$.

\section{Conclusions}

HIV-positive women are at high risk of coinfection by HPV oncogenic subtypes. This study confirms the need to integrate the screening of cervical cancer in HIV care protocols in Burkina Faso. Further investigations should be continued for the establishment of vaccine that matches all genotypes circulating in the country.

Published: 25 May 2012

doi:10.1186/1742-4690-9-S1-P36

Cite this article as: Dkigma et al: Genotype characterization of human papillomavirus in women infected and uninfected with HIV in Ouagadougou, Burkina Faso. Retrovirology 2012 9(Suppl 1):P36.

Submit your next manuscript to BioMed Central and take full advantage of:

- Convenient online submission

- Thorough peer review

- No space constraints or color figure charges

- Immediate publication on acceptance

- Inclusion in PubMed, CAS, Scopus and Google Scholar

- Research which is freely available for redistribution 